\title{
Short-range spatial variability of soil physico-chemical variables related to earthworm clustering in a Neotropical gallery forest
}

\author{
Juan-José Jiménez ${ }^{\mathrm{a}, \mathrm{c}, \dagger}$, Thibaud Decaëns ${ }^{\mathrm{b}}$, Edgar Amézquita ${ }^{\mathrm{c}}$, Idupulapati Rao ${ }^{\mathrm{c}}$, \\ Richard J. Thomas ${ }^{\mathrm{e}} \&$ Patrick Lavelle $\mathrm{e}^{\mathrm{c}, \mathrm{d}}$ \\ ${ }^{a}$ Pyrenean Institute of Ecology (IPE), Consejo Superior de Investigaciones Científicas (CSIC), Jaca (Huesca), E- \\ 22700, Spain \\ ${ }^{b}$ Laboratoire d'Ecologie, UPRES-EA 1293, UFR Sciences, Université de Rouen, F-76821 Mont Saint Aignan \\ Cedex, France \\ ${ }^{c}$ Centro Internacional de Agricultura Tropical (CIAT), AA 6713, Cali, Colombia \\ ${ }^{d}$ Laboratoire d'Ecologie des Sols Tropicaux, IRD, 32 Av. H. Varagnat, F-93143 Bondy, France \\ ${ }^{e}$ United Nations University, Institute for Water, Environment and Health (UNU-INWEH), 175 Longwood Road \\ South, Hamilton, ON L8P OA1, Canada
}

${ }^{a}$ Corresponding author (present address)

$\dagger$ Address during the study: Laboratoire d'Ecologie des Sols Tropicaux, Institute de la Recherche pour le Développement (IRD), 32 Av. H. Varagnat, F-93143 Bondy, France

Tel: ++34974356963

Fax: ++34974 363222

E-mail: jjimenez@ipe.csic.es 


\begin{abstract}
In this study, we investigated the spatial distribution of an earthworm community together with the heterogeneity of selected soil properties in a gallery forest (GF) of the Colombian "Llanos". We performed fine-scale spatial variability by intensively sampling 100 points distributed in the nodes of a regular grid with $5 \mathrm{~m}$ inter-sample distance. Non-parametric statistics were used and included SADIE analysis and partial Mantel test, in addition to geostatistics (semi-variograms) and correlogram computation. Our results indicated that the spatial distribution of earthworms was characterized by areas of presence (patches) and absence (gaps), although the general pattern was random at the scale of this study $(<5 \mathrm{~m})$, while soil physico-chemical characteristics showed a clumped spatial distribution. Contrary to previous results reported for the nearby savanna, a significant spatial association was found for two competing endogeic species Andiodrilus sp. and Glossodrilus sp. in the GF. Semivariograms of soil environmental factors were adjusted to model families most commonly used (spherical and linear), and correlograms for earthworms showed significant positive and negative spatial autocorrelation for lag distances $<15 \mathrm{~m}$ and $>30 \mathrm{~m}$, respectively. Partial Mantel test revealed specific significant relationships between soil variables and some species. The earthworm community of the GF displayed a random structure in a spatially clumped soil environment, and our results suggested that spatial distribution observed for some species could be the result of preferential selection of soil environmental factors. In other words, soil heterogeneity contributed to the formation of population patches for some earthworm species. The variability of suitable sites (resource availability patchiness) exerted an influence in the spatial distribution of earthworms at the scale used in this study, and we identified the spatial scale at which both environmental heterogeneity could influence and express earthworm impact on soil properties.
\end{abstract}

Key words: Earthworms; Spatial Distribution; Variograms; Correlograms; Mantel Test; Soil Fauna; Community Assembly; Gallery Forest. 


\section{Introduction}

The spatial distribution of earthworms is generally clumped and characterized by an alternation of high- and low-density population patches of several tens of meters (Jiménez et al. 2001; Nuutinen et al., 1998; Rossi and Nuutinen, 2004), although regular patterns have also been described at short scales (Thomas et al., 2008). The spatial segregation of these discrete patches have been interpreted as the result of environmental factors, i.e., plant cover and soil properties, and internal population processes, i.e., reproduction rates and dispersal mode (Robertson and Freckman, 1995; Rossi et al., 1997; Rossi and Quénehérvé, 1998; Decaëns and Rossi, 2001; Jiménez et al., 2001; Ettema and Wardle, 2002; Whalen, 2004; Jiménez et al., 2006; Barot et al., 2007; Matthieu et al., 2010). Long-term field studies on earthworm population dynamics and dispersal modes are not abundant and this restricts generalizations about the mechanisms explaining the observed population aggregated distribution.

Natural communities are assembled within the boundaries imposed by the abiotic environmental requirements and the interactions between species (Beleya and Lancaster 1999). Process of community assembly implies that a series of abiotic and biotic filters sift species out of a regional pool (Weiher and Keddy, 1995). In niche theory, competition is considered as one of the driving force structuring species assemblages in communities. By contrast, community patterns can also be generated by random processes according to neutral theory (Gotelli and Ellison, 2002). The latter has been reconciled with niche concepts under theoretical frameworks (Leibold and McPeek, 2006). Regarding earthworms, inter-specific competition has been 
demonstrated in shaping distribution of assemblage patches in tropical savannas (Jiménez and Rossi, 2006; Jiménez et al., 2006; Decaens et al., 2009), where species pairs showed significant spatial segregation usually associated with a high degree of niche overlap.

The influence of soil spatial variability in shaping population patches of earthworm assemblages is poorly understood. Despite its importance, understanding the driving factors that explain the spatial structure of soil communities continues to be a blackbox in spatial ecology studies, as these have been overlooked when compared to studies on above-ground biota (Ettema and Wardle, 2002). Several authors have demonstrated that earthworm communities are organised in mosaics of patches characterised by dominant species assemblage with detectable effects on soil properties (Decaëns and Rossi, 2001; Rossi, 2003b). Moreover, these patterns can be significantly stable at a temporal scale of few years (Jiménez et al., 2006). Species within natural communities show differences in resource use and ecological requirements. Therefore, earthworm species might be deterministically shaped by such spatial variability of soil properties, if a spatial structure of soil resources is observed.

Spatial analysis has proven to be an important tool to explain the patterns and mechanisms behind the structuring of population patches in soil community studies. Specific and spatially explicit designed surveys are needed and these are not abundant in the literature. Consequently, new data sets are required that are related to the scale and magnitude of the spatial patterning and emphasize the relationship between the spatial patterning of soil communities and usable resources in the soil. A specific 
detailed spatially explicit sampling design would allow us to address the question of soil environmental heterogeneity in structuring earthworm patches. In this study, our objective was to unravel the spatial pattern of soil organisms at short scales, and its relationship with soil environmental factors in order to test whether soil environmental variability was responsible for the patterns observed. We hypothesized that the spatial distribution of the earthworm community present in a gallery forest (GF) of the Colombian "Llanos" was structured by the aggregated pattern of soil properties at short spatial scales, i.e. $<50 \mathrm{~m}$. Our approach was based in the use of rigorous spatial statistics to unveil the mechanisms explaining earthworm species-environment relationships, and also to infer possible mechanisms of inter-specific competition.

\section{Materials and methods}

\subsection{Study site}

Fieldwork was carried out at the former Carimagua research station (CORPOICACIAT agreement) in the well-drained isohyperthermic savannas of the Colombian “Llanos" ( $4^{\circ} 37^{\prime} \mathrm{N}, 71^{\circ} 19^{\prime} \mathrm{W}, 150 \mathrm{~m}$ a.s.1.). The study area is a young alluvial plain consisting of deposits of Pleistocene and Holocene sediments of Andean origin. Gallery forests, with a similar floristic composition to the Amazonian rainforest follow a dense braided drainage network of rivers and water flows ("caños") toward the large Orinoco catchment. The climate in the area is sub-humid tropical and follows a unimodal regime, with a marked dry season from December to March, and a yearly average precipitation and temperature of $2,280 \mathrm{~mm}$ and $26^{\circ} \mathrm{C}$, respectively. The main soil types in the area are Oxisols in the upland savannas and Ultisols in the lowlands, 
with high acidity, i.e. $\mathrm{pH}\left[\mathrm{H}_{2} \mathrm{O}\right]=4.5, \mathrm{Al}$ saturation $>90 \%$, and low cation exchange capacity (CEC) (CIAT data).

Sampling was done in a gallery forest located in "La Reserva" bordering the Carimagua Lake. This is a secondary forest with several abundant tree species like Dendropanax arboreum ("Cambusil", Araliaceae), Enterolobium spp. ("caracaro", Leguminosae), Ficus spp. (Moraceae), Jacaranda copaia (“Machaco”, Bignoniaceae), Copernicia tectorum ("Palmiche", Caesalpiniaceae), and Cecropia sp. ("Yarumo", Cecropiaceae). Shore vegetation ("Morichal") includes Mauritia flexuosa, M. minor and Mauritiella ("Moriche", Palmaceae). Other plant species reported in "La Reserva" gallery forest are: Attalea maripa ("Palma Cucurita", Palmaceae), $\underline{\text { Nectandra }}$ membranacea (Sw.) Griseb. (“Laurel”, Lauraceae), Didymopanax morototoni (Aubl.) Decne \& Planch ("Tórtolo", "Yagrumo", Araliaceae), Virola sp. ("Cuajo", Myristicaceae), and Hymenaea courbaril (“Algarrobo”, Caesalpiniaceae) (Ramia 1974). Local names can be consulted in http://www.biovirtual.unal.edu.co/diccionario/consultar.html).

\subsection{Earthworms and soil sampling}

We assessed fine-scale spatial variability of earthworms and soil through intensive sampling in the nodes of a 10x 10 points regular grid with $5 \mathrm{~m}$ inter-sample distance. Earthworm species were taken from $25 \times 25 \mathrm{~cm}^{2}$ down to $20 \mathrm{~cm}$ depth soil pits. We selected a $5 \mathrm{~m}$ inter-sample distance based on previous results from sampling earthworm assemblages in a savanna environment, where inter-sampling distance was 10 m (Decaëns and Rossi, 2001; Jiménez et al., 2001; 2006). The number of 
individuals for each species was annotated and earthworms were released back to the soil. Prior to pit excavation litter was hand sorted from $1 \mathrm{~m}^{2}$ quadrats and conserved in plastic bags.

We performed a very detailed sampling effort for soil environmental variables. Four soil cores were taken in the four sides of the dug pit at each sampling point.

1. Soil core 1: Bulk density was determined with the core method (soil dry mass per volume) using a $5 \times 5 \mathrm{~cm}$ steel cylinder; soil water content (soil water per volume, and soil water per dry mass) were determined gravimetrically.

2. Soil core 2: Soil organic C (SOC) determination in the $0-5$ and $5-10 \mathrm{~cm}$. The soil was oven dried at $75^{\circ} \mathrm{C}$ for $48 \mathrm{~h}$ and finely grounded. SOC concentration was determined with the colorimetric method after acid digestion in $\mathrm{H}_{2} \mathrm{SO}_{4}$, and the Kjeldahl method was used for total N. Available P was determined with the Bray-II extraction method.

3. Soil core 3: Steel cylinders of $15 \mathrm{~cm}$ depth and $10 \mathrm{~cm}$ diam. were taken to asses size-class aggregate distribution. Approximately, $100 \mathrm{~g}$ of air-dried soil was used for standard dry-sieving through a sieve column of 4.75, 2.0, 1.0, 0.5 and $0.250 \mathrm{~mm}$ for $30 \mathrm{~min}$ in a mechanical shaker.

4. Soil core 4: A $15 \times 10 \mathrm{~cm}$ metal cylinder was used for assessment of root length and biomass. In the lab the soil core was dispersed in water and poured through a set of sieves of 2 and $0.5 \mathrm{~mm}$. Fine $(0.5-2 \mathrm{~mm})$ and coarse roots $(>2 \mathrm{~mm})$ were hand-picked from the sieve contents. 
Finally, soil structure was quantified indirectly by measuring soil resistance to penetration. At each sampling point three readings were recorded and graphed on paper cards with a penetrometer. Soil penetration resistance was determined when topsoil moisture content was close to field capacity (pF $2.8=38 \% \mathrm{v} / \mathrm{v})$.

\subsection{Spatial distribution of earthworms}

\subsubsection{SADIE analysis (cluster and gap identification)}

The degree of species aggregation was assessed with the analysis of their spatial distribution in the surveyed area $\left(45 \times 45 \mathrm{~m}^{2}\right)$. Count data of earthworms (individuals per sampling point) were analysed with the Spatial Analysis Distance IndicEs (SADIE) red-blue methodology (Perry, 1998; Perry et al., 1999). This spatial analysis is specifically addressed to handle count data collected at spatially-referenced sampling units. A global index of aggregation, namely $I_{a}$ is computed and its value indicates the type of spatial distribution, e.g., random if the $I_{a}=1$, aggregated if $I_{a}>1$, and regular if $\mathrm{I}_{\mathrm{a}}<1$ (Perry et al. 1999).

Later, a cluster index is computed for each sampling point. A cluster is defined here as an area of either relatively high (patch) or low (gap) mean density. This local cluster index is positive $\left(\mathrm{v}_{\mathrm{i}}\right)$ or negative $\left(\mathrm{v}_{\mathrm{j}}\right)$ for a sample that has more or less individuals, respectively, than expected by the null hypothesis of complete spatial randomness. These indices permit a direct identification of samples that contribute to patches or gaps or that correspond to areas where density displays no significant departure from the average value across the study plot. The individual significance of 
each sampling unit is assessed using the heuristic thresholds of 1.5 and -1.5 (see Perry et al., 1999 for a complete description of the method).

Once the clusters were isolated and determined (patch, gap or non significant values), they were described using landscape metrics (Forman, 1995). A patch or gap consists of at least one sample location where the $v_{i}$ or $v_{j}$ index is significant. A single cluster is formed by adjacent sample locations having significant index values. Clusters were described as follows:

$\mathrm{NC}=$ number of clusters of a given type (i.e. patch, gap or random), PLAND $=$ the percentage of the plot area included in the corresponding cluster type, and $\mathrm{LCI}=$ the percentage of the plot area comprised by the largest cluster of each type.

Finally, an association index was computed to test for the spatial association or dissociation between species' pairs (Perry and Dixon, 2002). The local association indices calculated from their individual sampling-unit clustering indices are correlated between species' pairs. The observed value of the association index is tested against the null hypothesis of complete spatial independence of counts, which is based on random permutations (Perry and Dixon, 2002). SADIE statistics was performed with the available software kindly provided by Dr. J. Perry (Rothamsted Research group, England). Graphical maps of patches and gaps were depicted with Surfer v.6.04 (Golden Software Inc., Colorado, USA). 


\subsubsection{Geostatistics and partial Mantel test}

Soil organism horizontal distribution is usually clumped or aggregated. The degree of autocorrelation is assessed with the semi-variogram, the function describing the spatial pattern of any variable that relates the semi-variance $\gamma(h)$ between two variables with increasing distance (Cressi, 1993) using the algorithm:

$$
\gamma(h)=\frac{1}{2} M(h) \sum_{i=1}^{M(h)}\left(x_{i}\right)-Z\left(x_{i}+h\right)_{-}^{2}
$$

, where $M(h)$ is the number of sample pairs at each distance interval $h$ ("lag") and $Z\left(x_{i}\right)$ and $Z\left(x_{i}+h\right)$ the values of the variable at any two places separated by a lag $h$.

The more alike the values separated by a given distance, the lower the semivariance. In the presence of spatial autocorrelation, the lag distance is increased until $\gamma(h)$ reaches a maximum value called the "sill" variance for a given distance interval (the range, a). The range defines the limit of spatial dependence of the variable concerned, i.e., the maximum distance at which pairs of observations influence each other. A third parameter in variogram estimation is the nugget effect, i.e., the variance within sampling units, and represents unexplained or random variance, which is often attributed to measurement error or variability at a scale smaller than the sampling scale (Cressi, 1993).

Estimated values of $\gamma(h)$ are adjusted to a several authorized theoretical models in the semi-variogram (McBratney and Webster, 1986; Rossi et al., 1992). The most 
commonly used models are the spherical, Gaussian and exponential, which assume that there is no spatial dependence for distances larger than the range. In this study the number of sampling units was large enough to reliably estimate semi-variograms (Webster and Oliver, 1982). The semi-variogram is further used to estimate values of the variables at non-sampled points by "kriging" interpolation (Cressi, 1993). The Gstat software was used to compute the variograms and kriging, and Sigmaplot 11.0 (C Systat software Inc., 2008) for depicting contour maps after kriging procedure.

When analysing spatial data sets ignoring spatial autocorrelation can give confusing results (Beale et al., 2010). We performed correlogram analysis with the Moran's $I$ index to assess the significance of the spatial pattern of earthworms and soil variables. The correlogram is the function on which the spatial pattern of a given variable and the scale at which it expresses is represented (Sokal and Oden, 1978). Values of the Moran's I index are plotted in the correlogram to show the changes of autocorrelation coefficient with increasing distance classes and its significance (Rossi, 1997; Overmars et al., 2003). They can be used to quantify the spatial dependency per distance class or lag. Data were allocated to 10 distance classes for convenience with $5.8 \mathrm{~m}$ lag distance, slightly higher than the inter-sample distance used. For the computation of the correlogram a minimum of 50 pairs of points or higher were taken into account in each distance class. The overall statistical significance of the correlogram was performed with a Bonferroni corrected probability procedure (Oden, 1984). The corrected $\mathrm{p}^{*}$ was $\alpha^{\prime}=\alpha / \mathrm{k}$, with $\mathrm{k}$ the number of distance classes and $\alpha<0.05$ the global significance level (Oden, 1984). The correlogram is statistically 
significant when at least one coefficient is significant at the corrected $\mathrm{p}^{*}$ of $0.05 / 10=$ 0.005 (Cooper, 1968). Homoscedasticity of data frequency distribution was tested with a Kolmogorov-Smirnov test, and a Box-Cox transformation was used to reduce the asymmetry of the frequency distribution when normality assumption was not achieved (Sokal and Rohlf, 1995). The software "PASSaGE" v.2 was used for the computation of Moran's I spatial autocorrelation index.

The relationship between the spatial pattern of earthworm density and soil environmental variables was assessed with the partial Mantel test (Mantel, 1967) to search for the relationship between two distance matrices that reflect the spatial structure of two given variables (Legendre and Fortin, 1989). The position of sampling points may determine false or spurious relationships, simply due to the autocorrelation of variables, i.e. to their spatial location in the space. The partial Mantel test allows testing for the correlation between both matrices while controlling the effect of the spatial position by a third space distance matrix (Smouse et al., 1986; Legendre, 1993) which represents the spatial sampling coordinates (Legendre and Troussellier, 1988). We used a permutation test (10,000 permutations) to detect the statistical significance of the partial Mantel test at $\alpha<0.05$ level (Legendre and Fortin, 1989).

\subsection{Probability level correction: False discovery rate procedure}

A correction to probability level was done by using the false discovery rate (FDR) procedure for multiple comparisons (Benjamini and Hochberg, 1995) to adjust the $\alpha<0.05$ significant level. The rationale behind this procedure is that the power of 
multiple tests is optimized while controlling for the proportion of significant results that could actually be Type I errors (García, 2004). The p values from the individual tests are used to perform the corrections and search for significant differences at the corrected probability level. The comparison starts with the highest $\mathrm{p}$ value obtained from the individual tests and then each $\mathrm{p}$ is checked until the first $\mathrm{p}$ that meets the requirement (Benjamini and Hochberg, 1995). Final p value corresponded to the following correction:

$$
\mathrm{P}(\mathrm{i}) \leq(\alpha / \mathrm{m}) * \mathrm{i}
$$

, where $\mathrm{m}$ is the number of tests and $\mathrm{i}$ is the test ranked in ascending order, i.e. $\mathrm{P}(1)$ $\leq \ldots . \leq \mathrm{P}(\mathrm{m})$, and $\mathrm{H}(\mathrm{i})$ denotes the null hypothesis corresponding to $\mathrm{P}(\mathrm{i})$.

\section{Results}

\subsection{Earthworm community structure}

In the gallery forest 688 earthworms were recorded representing the main ecological categories and belonging to seven undescribed species all new to science (Table 1). Some of them are also normally present in the natural savanna while others were only restricted to this ecosystem (J. Jiménez, unpubl.) Two epigeic species differing in size were recorded: Aymara sp., which is also present in the savanna, and a large antero-dorsal dark-red colored earthworm (new genus sp.1) which is only restricted to GF. Glossodrilus sp. and Andiodrilus sp. are two medium-sized endogeic species that are also present in the savanna and their abundance was relatively high, while only one individual was recorded for Andiorrhinus sp. from all the 100 sampling 
points (Table 1). Martiodrilus sp., which is also normally found in the savanna, is a large anecic species. The new genus 2 (Ocnerodrilidae) and Martiodrilus sp. were the most abundant species, the former being the smallest species and normally found in sites of high organic content, like in-soil faeces produced by other earthworm species (Jiménez et al., 1998).

\subsection{Spatial analysis: earthworm clusters}

The SADIE analysis revealed that earthworm spatial distribution followed a random distribution in the sampled area of the GF, except for Aymara sp., which had a significant $I_{a}$ index (Table 2). On the other hand, this analysis suggested the presence of small patches and gaps of varying size in all species. Clusters of earthworm distribution occupied different areas within the sampled plot, the size of which varied significantly among species. The number of clusters (i.e. patches or gaps) obtained for all earthworm species ranged from 2 to 7 (Table 2), and the corresponding graphical representation is depicted in Figure 2.

SADIE association index between earthworm species pairs indicated a significant positive species' association between $\underline{\text { Andiodrilus }} \mathrm{sp}$. - Glossodrilus $\mathrm{sp} .(\mathrm{r}=0.2883 ; \mathrm{P}$ $=0.0065)$, and $\underline{\text { Martiodrilus }}$ sp. - new genus $2(\mathrm{r}=0.2650 ; \mathrm{P}=0.0036)$, while significant dissociation $(\mathrm{r}=-0.2013 ; \mathrm{P}=0.9870)$ was observed for Aymara sp. -

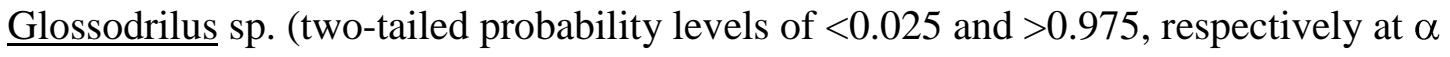
$=5 \%)$. Non significant trend towards dissociation was observed for Aymara sp. with Andiodrilus sp., new genus 1 , and new genus 2 . On the other hand, the coefficient of association indicated a non-significant tendency towards association for Andiodrilus 
sp. - new genus 1, Glossodrilus sp. - new genus 1, and Glossodrilus sp. - new genus 2.

\subsection{Geostatistical analysis and partial Mantel test}

The semi-variograms for SOC (Figure 2a), N concentration, P content at $0-5 \mathrm{~cm}$ (Figure 2b), C:N, FiRL, FiRW, CoRL and soil aggregates were adjusted to the spherical model, while $\mathrm{P}$ content at 5-10 cm, penetration resistance and hydraulic conductivity (Figure 2c) were adjusted to the linear type (Table 3). The range of the spatial structure varied from $4 \mathrm{~m}$ to ca. $400 \mathrm{~m}$ for SOC at $5-10 \mathrm{~cm}$ and CoRL, respectively. No spatial structure was observed for some variables, i.e., the variance fluctuated around the nugget variance with increasing distance for moisture content, bulk density, proneness to compaction (Figure 2d) and CoRW (Table 3).

The correlograms calculated for earthworm species were significant except for Glossodrilus sp. at the Bonferroni corrected P (Table 4). Positive spatial autocorrelation was observed at a lag distance of $<6 \mathrm{~m}$ for Aymara $\mathrm{sp}$. and new genus 1, while it was $8 \mathrm{~m}$ for new genus 2 , from 23 to $35 \mathrm{~m}$ for Andiodrilus sp. and $49 \mathrm{~m}$ for Martiodrilus sp. On the other hand, negative spatial autocorrelation was observed for

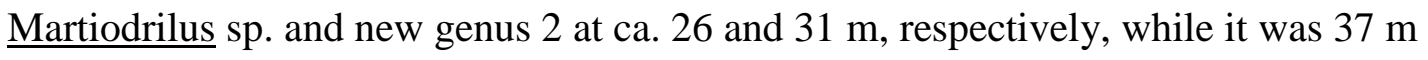
for Andiodrilus sp. (Table 4).

Finally, the correlograms computed for soil variables were significant (Table 5), and a common pattern was observed: positive and negative spatial autocorrelation at $<20 \mathrm{~m}$ and $>30 \mathrm{~m}$ lag distance, respectively (Table 5). The significance of the spatial 
pattern of soil variables revealed by the correlograms indicated a general pattern: for nutrient-related soil variables, especially P and C: $\mathrm{N}_{5-10}$, Moran's I index yielded positive spatial autocorrelation for lag distances up to $23 \mathrm{~m}$ and negative for $35 \mathrm{~m}$ onwards. Spatial autocorrelation for litter was positive for distance lags 1 and 6, and negative for distance lags 4 and 8 , what could be an indication of the high heterogeneity in plant cover in the survey plot.

A significant correlation was observed between the spatial distribution of soil variables and earthworms with partial Mantel test (Table 6). For example, the relationship between new genus 1 and SOC concentration at $0-5 \mathrm{~cm}$ (as revealed by CoIA) was significant. In the case of Andiodrilus sp. the relationship with bulk density was not significant at the corrected probability level. Andiodrilus sp. only showed a negative significant correlation with soil physical properties like resistance to penetration and the amount of 1-2 mm size-class aggregates (Table 6). On the contrary, a clear correlation was observed between Aymara sp. and microaggregates $(<0.250 \mathrm{~mm})$ and the length of fine roots. A negative significant correlation with $\mathrm{C}$ and $\mathrm{C}: \mathrm{N}$ ratio at $5-10 \mathrm{~cm}$ soil depth, $\mathrm{BD}$ and proneness to compaction was observed for new genus 1 . On the contrary, a positive relationship was observed for $\mathrm{C}$ and $\mathrm{C}: \mathrm{N}$ ratio in the 0-5 cm depth and hydraulic conductivity. Glossodrilus sp. and new Genus 2 were negatively and positively correlated with aggregates ranging from 2 to $5 \mathrm{~mm}$ and the $\mathrm{C}: \mathrm{N}$ ratio at $5-10 \mathrm{~cm}$ depth, respectively. Finally, no significant correlation was observed between soil environmental variables and the spatial distribution of Martiodrilus sp. (Table 6). 


\section{Discussion}

\subsection{Scale and significance of earthworm short-range structures}

Earthworm species displayed a patchy distribution with different number of clusters and gaps of varying size. The area covered by significant clusters and gaps was small, and clusters map also revealed that earthworms occurred in areas where clustering was not significantly different from randomness. The resulting general pattern identified with SADIE analysis was random, except for Aymara sp. In general, few studies have dealt with small-scale spatial patterns in earthworm populations. For instance, Rossi (2003a) showed that earthworm populations were highly autocorrelated at scales of less than $10 \mathrm{~m}$, with patches of endogeic earthworms from 2 to $8 \mathrm{~m}$ diameter in an African savanna. In our study, the size of patches was smaller, i.e. 5-15 m, than those reported for the nearby savanna, between 30-40 m (Decaëns and Rossi, 2001; Jiménez et al., 2001; Jiménez and Rossi, 2006). SADIE analysis has been successfully used in studies with beetles (Blackshaw and Vernon, 2006) and termites (Donovan et al., 2007).

Different species associations were found in the GF compared to results obtained in the nearby savanna. The negative association index computed for Glossodrilus sp. and Aymara sp. in the GF might imply a process of inter-specific competition between both species, while Andiodrilus sp. and Glossodrilus sp. which were demonstrated to be competing species in the savanna (Jiménez and Rossi, 2006; Jiménez et al. 2006) seemed not to be in competition in the GF, although further research is needed. Soil heterogeneity might have allowed spatial co-existence between competing species. 
Negative associations between species pairs may arise from either heterogeneity of environmental factors or stochastic processes as reported in studies with ant communities (Ribas and Schroereder, 2002).

The size of population patches at the time of sampling, as indicated by the correlogram analysis and its significance, was smaller for epigeic than for endogeic and anecic species within the community. The fact that epigeic species tended to be more aggregated at shorter distances than endogeic and anecic species could be the result of low population density at the plot scale, high reproduction rates, short life cycle (annual), and r-strategies (high production of cocoons), which are characteristic life history traits of epigeic species (Lavelle, 1981).

\subsection{Soil environmental variability and spatial distribution of earthworm species}

The spatial pattern of soil properties at the scale of our study ranged from a few meters to hundreds of meters, depending on the soil parameter considered. Soil forming factors like parent material, climate, vegetation, topography, and biological activity can be responsible for the spatial variability of soil physical and chemical properties. In our study, it is worth noticeable that the range of soil nutrient-related properties was $<10 \mathrm{~m}$, whereas that observed for soil physical properties was several tens of meters (Table 5). It was also worth pointing out that the correlogram for SOC concentration at $0-5 \mathrm{~cm}$ depth was not significant, although positive spatial autocorrelation was found at distance lag of $<5 \mathrm{~m}$, and negative above $50 \mathrm{~m}$. 
The role of abiotic factors in shaping communities and species preference for different environmental conditions has been demonstrated for several soil taxa by several authors (Jackson, 1984; Dunson and Travis, 1991; Morrison, 1996; Ribas and Schoereder, 2002). The spatial distribution of earthworms was partly the result of species' responses to soil environmental heterogeneity. Our results indicated the existence of soil environmental heterogeneity that was expressed at several scales. In the computed variograms for soil variables, the presence of different sills and ranges clearly revealed spatially nested structures. Plant composition and cover was highly heterogeneous, and a diverse plant community produces litter of different quality and quantity resulting in higher resource heterogeneity compared with the herbaceous savanna. Different plant species are likely to support important levels of heterogeneity of belowground properties (Wardle, 2002). Soil properties were patchily distributed and the spatial scale at which both environmental heterogeneity and species influence on soil, i.e., the "functional domain” (sensu Lavelle, 1997) was detected. At larger scales factors affecting the spatial distribution of soil organisms are gradients in SOM and vegetation structure (Ettema and Wardle, 2002), while at shorter scales $(<10 \mathrm{~m})$ earthworm spatial distribution could be influenced by local factors like plant characteristics, soil local conditions (moisture) and micro-topography. We can thus hypothesize that the short-range spatial structures observed in earthworm populations was the result of local environmental variation, such as root architecture or small scale spatial patterns of the above-ground community, the so-called "single-tree effect" (Wardle and Lavelle, 1997). 
Non-random species' spatial patterns may also arise from habitat heterogeneity (Bell, 2005). In our study, earthworm spatial distribution was environmentally controlled by spatially distributed soil properties for several species, i.e., there was a spatial dependence. Discrete earthworm population patches were related to specific soil properties' zones within the surveyed plot. Moreover, the relationship seemed to be species-specific, i.e., the Mantel test revealed that certain soil variables were significantly related with only one species, except the C:N ratio $(5-10 \mathrm{~cm})$ and the percentage of 1-2 mm size-class aggregates. Patches of new genus 1 were encountered in areas of high SOC and $\mathrm{N}$ concentration in the topsoil $(0-5 \mathrm{~cm})$, and negatively correlated with sites of high soil bulk density and compaction. This might be an indication of preferential resource exploitation of this epigeic species for high organic content areas. Another example is provided by new genus 2, which is a small endogeic earthworm that was positively spatially correlated with areas of high C:N ratio (5-10 $\mathrm{cm})$. In the nearby savanna this species was normally found feeding into cast-filled burrows of the anecic Martiodrilus (Jiménez et al., 1998). This supports the idea that species presence is linked to environmental factors at very short scales, and not only as a result of internal population processes.

By contrast, patches of Andiodrilus sp. were generally established in areas of high soil bulk density and compaction, although not significantly. Endogeic earthworms are characterized by their effects on soil structure (Blanchart et al., 1997), and excessive cast deposition in Amazonian pastures by the pantropical earthworm Pontoscolex corethrurus (Glossocolecidae) lead to soil compaction problems and plant productivity decrease due to reduced water infiltration (Chauvel et al., 1999). In our study, the 
reported spatial distribution of Andiodrilus sp. and its relation with areas of high soil bulk density and compaction suggests an impact on soil structure at very short-scales. In other words, bulk density would tend to increase in the patches of Andiodrilus sp. due to compact dejections released in the surrounding soil and thus contributing to existing soil heterogeneity.

\section{Concluding remarks (new)}

Our study clearly demonstrated that the earthworm community was randomly distributed at short spatial scales, even though small patches of varying population density were detected in the surveyed plot. The specific spatially designed sampling protocol used in this study, an inter-sample distance of $5 \mathrm{~m}$, allowed us to reveal shortscale clusters in earthworm spatial distribution. In a spatially heterogeneous environment where resources used by the earthworm community follow a clumped distribution, population of species' assemblages were distributed in patches. Even in the presence of high resource availability sites earthworm species showed positive autocorrelation at short spatial scales, while it was negative at larger scales.

The analysis performed was relevant to unveil the influence of environmental factors in shaping short-scale earthworm patches, and the spatial relationship between soil properties and earthworms was significantly specific. Spatial segregation of competitive species pairs' revealed in the savanna, i.e. Andiodrilus sp. and Glossodrilus sp., seemed to be otherwise allowed in the GF. The reason could be related to the existence of a less-constrained environment with large resource availability, and this also resulted in random spatial distribution of the earthworm 
community. The resource availability patchiness exerted an influence in the spatial distribution of new genus 1 at the scale used in this study. Besides, the spatial variability of soil physical properties was the result of the activity of Andiodrilus $\mathrm{sp}$. As a consequence, soil environmental heterogeneity and species influence on certain soil properties explained the spatial patterns observed and played a key role in structuring earthworm clusters at short scales in the GF. Spatially structured communities of soil organisms may suggest that some species respond to the spatial variability of soil resources, although further studies are required to quantify the size and dynamics of patches of earthworms in different ecosystems at a global scale.

\section{Acknowledgements}

Local names for tree species of the gallery forest are those specifically used in the Carimagua region, and field assistants Jose García, Salvador Rojas and Guillermo Murcia are deeply appreciated for their help in field sampling and sharing their knowledge. CIAT and IRD provided financial and logistic support during field work. We would like to thank research assistant Jaumer Ricaute for root analysis at CIAT lab. Thanks are extended to JeanPierre Rossi (INRA) for fruitful discussions on spatial statistics tools, and Michael S. Rosenberg (Arizona State University) for availability and permission to use PASSaGE software. Finally, the useful comments of two anonymous referees and assigned editor are greatly acknowledged.

\section{References}


Barot, S., Rossi, J.P., Lavelle, P., 2007. Self-organization in a simple consumer-resource system, the example of earthworms. Soil Biology and Biochemistry 39, 2230-2240.

Beale, C.M., Lennon, J.J., Yearsley, J.M., Brewer, M.J., Elston, D., 2010. Regression analysis of spatial data. Ecology Letters13, 246-264.

Belyea, L.R., Lancaster, J., 1999. Assembly rules within a contingent ecology. Oikos 86, 402416.

Bell, G., 2005. The co-distribution of species in relation to the neutral theory of community ecology. Ecology 86, 1757-1770.

Benjamini, Y., Hochberg, Y., 1995. Controlling the false discovery rate: A practical and powerful approach to multiple testing. Journal of the Royal Statistics Society B 57, 289300.

Blackshaw, R.P., Vernon, R.S., 2006. Spatiotemporal stability of two beetle populations in non-farmed habitats in an agricultural landscape. Journal of Applied Ecology 43, 680689.

Blanchart, E., Lavelle, P., Braudeau, E., Bissonais, Y.L., Valentin, C., 1997. Regulation of soil structure by geophagous earthworm activities in humid savannas of Cote d'Ivoire. Soil Biology and Biochemistry 29 (3/4), 431-439.

Chauvel, A., Grimaldi, M., Barros, E., Blanchart, E., Desjardins, T., Sarrazin, M., Lavelle, P., 1999. Pasture damage by an Amazonian earthworm. Nature 398, 32-33.

Cooper, D.W., 1968. The significance level in multiple tests made simultaneously. Heredity 23, 614-617.

Cressi, N.A.C., 1993. Statistics for Spatial Data. John Wiley and Sons, New York.

Decaëns, T., Jiménez, J.J., Rossi, J.-P., 2009. A null-model analysis of the spatio-temporal distribution of earthworm species assemblages in Colombian grasslands. Journal of Tropical Ecology 25, 415-427. 
Decaëns, T., Rossi, J.-P., 2001. Spatio-temporal structure of earthworm community and soil heterogeneity in a tropical pasture. Ecography 24, 671-682.

Donovan, S.E., Griffiths, G.J.K., Homathevi, R., Winder, L., 2007. The spatial pattern of soildwelling termites in primary and logged forest in Sabah, Malaysia. Ecological Entomology 32, 1-10.

Dunson, W.A., Travis, J., 1991. The role of abiotic factors in community organization. American Naturalist 138, 1067-1091.

Ettema, C.H., Wardle, D.A., 2002. Spatial soil ecology. Trends in Ecology and Evolution 17, $177-183$.

Forman, R.T.T., 1995. Land mosaics: the ecology of landscapes and regions. Cambridge University Press, Cambridge.

García, L.V., 2004. Escaping the Bonferroni iron claw in ecological studies. Oikos 105, 657663.

Gotelli, N.J., Ellison, A.M., 2002. Assembly rules for New England ant assemblages. Oikos 99, 591-599.

Jackson, D.A., 1984. Ant distribution patterns in a Cameroonian cocoa plantation: investigation of the ant mosaic hypothesis. Oecologia 62, 318-324.

Jiménez, J.J., Decaëns, T., Rossi, J.P., 2006. Stability of the spatio-temporal distribution and niche overlap in Neotropical earthworm assemblages. Acta Oecologica 30, 299-311.

Jiménez, J.J., Moreno, A.G., Decaëns, T., Lavelle, P., Fisher, M.J., Thomas, R.J., 1998. Earthworm communities in native savannas and man-made pastures of the Eastern Plains of Colombia. Biology and Fertility of Soils 28, 101-110.

Jiménez, J.J., Rossi, J.P., 2006. Spatial dissociation between two endogeic earthworms in the Colombian "Llanos". European Journal of Soil Biology 42, S218-S224. 
Jiménez, J.J., Rossi, J.P., Lavelle, P., 2001. Spatial distribution of earthworms in acid-soil savannas of the eastern plains of Colombia. Applied Soil Ecology 17, 267-278.

Lavelle, P., 1981. Stratégies de reproduction chez les vers de terre. Acta Oecologica 2(2), 117133.

Lavelle, P., 1997. Faunal activities and soil processes: adaptive strategies that determine ecosystem function. Advances in Ecological Research 27, 93-132.

Legendre, P., 1993. Spatial autocorrelation: trouble or new paradigm? Ecology 74, 1659-1673.

Legendre, P., Fortin, M.-J., 1989. Spatial pattern and ecological analysis. Vegetatio 80, 107138.

Legendre, P., Troussellier, M., 1988. Aquatic heterotrophic bacteria: modelling in the presence of spatial autocorrelation. Limnology and Oceanography 33, 1055-1067.

Leibold, M.A., McPeek, M.A., 2006. Coexistence of the niche and neutral perspectives in community ecology. Ecology 87, 1399-1410.

Mantel, N., 1967. The detection of disease clustering and a generalized regression approach. Cancer Research 27, 209-220.

Mathieu, J., Barot, S., Blouin, M., Caro, G., Decaëns, T., Dubs, F., Dupont, L., Jouquet, P., Nai, P., 2010. Habitat quality, conspecific density, and habitat pre-use affect the dispersal behaviour of two earthworm species, Aporrectodea icterica and Dendrobaena veneta, in a mesocosm experiment. Soil Biol. Biochem. 42, 203-209.

McBratney, A.B., Webster, R., 1986. Choosing functions for semivariograms of soil properties and fitting them to sampling estimates. Journal of Soil Science 37, 617-639.

Morrison, L.W. 1996. Community organization in a recently assembled fauna: the case of Polynesian ants. Oecologia 107, 243-256. 
Nuutinen, V., Pitkänen, J., Kuusela, E., Widbom, T., Lohilahti, H., 1998. Spatial variation of an earthworm community related to soil properties and yield in a grass-clover field. Applied Soil Ecology 8, 85-94.

Oden, N.L., 1984. Assessing the significance of a spatial correlogram. Geographical Analysis $16,1-16$.

Overmars, K.P., de Koning, G.H.J., Veldkamp, A., 2003. Spatial autocorrelation in multi-scale land use models. Ecological Modelling 164, 257-270.

Perry, J.N., 1998. Measures of spatial pattern for counts. Ecology 79, 1008-1017.

Perry, J.N., Dixon, P., 2002. A new method for measuring spatial association in ecological count data. Ecoscience 9, 133-141.

Perry, J.N., Winder, L., Holland, J.M., Alston, R.D., 1999. Red-blue plots for detecting clusters in count data. Ecology Letters 2, 106-113.

Ribas, C.R., Schoereder, J.H., 2002. Are all ant mosaics caused by competition? Oecologia 131, 606-611.

Robertson, G.P., Freckman, D.W., 1995. The spatial distribution of nematode trophic groups across a cultivated ecosystem. Ecology 76, 1425- 1432.

Rossi, J.-P., 1997. Statistical tool for soil biology XI. Autocorrelogram and Mantel test. European Journal of Soil Biology 32(4), 195-203.

Rossi, J.P., 2003a. Clusters in earthworm spatial distribution. Pedobiologia 47, 490-496.

Rossi, J.P., 2003b. The spatiotemporal pattern of a tropical earthworm species assemblage and its relationship with soil structure. Pedobiologia 47, 497-503.

Rossi, J.-P., Lavelle, P., Albrecht, A., 1997. Relationships between spatial pattern of the endogeic earthworm Polypheretima elongata and soil heterogeneity. Soil Biology and Biochemistry 29 (3/4), 485-488. 
Rossi, J.P., Nuutinen, V., 2004. The effect of sampling unit size on the perception of the spatial pattern of earthworm (Lumbricus terrestris L.) middens. Applied Soil Ecology 27, 189-196.

Rossi, R.E., Mulla, D.J., Journel, A.G., Franz, E.H., 1992. Geostatistical tools for modeling and interpreting ecological spatial dependence. Ecological Monographs 62(2), 277-314.

Smouse, P.E., Long, J.C., Sokal, R.R., 1986. Multiple regression and correlation extensions of the Mantel test of matrix correspondence. Systematics Zoology 35, 627-632.

Sokal, R.R., Oden, N.L., 1978. Spatial autocorrelation in biology. 1. Methodology. Biological Journal of the Linnean Society 10, 199-228.

Sokal, R.R., Rohlf, F.J., 1995. Biometry: the principles and practice of statistics in biological research. W. H. Freeman and Co., New York.

Thomas, F., Rossi, J.-P., Decaëns, T., Grimaldi, M., Lavelle, P., da Silva Martins, P.F., Garnier-Zarli, E., 2008. Comparative analysis of Andiodrilus pachoensis casts in forests and pastures of South-Eastern Amazon (Brazil). European Journal of Soil Biology 44, $545-553$.

Wardle, D.A., 2002. Communities and ecosystems - Linking the aboveground and belowground components. Princeton University Press, Princeton. 392 p.

Wardle, D.A., Lavelle, P., 1997. Linkages between soil biota, plant litter quality and decomposition. In: Cadisch, G., Giller, K.E. (Eds.), Driven by Nature: Plant Litter Quality and Decomposition. CAB International, Wallingford, Oxon, UK, pp. 107-124.

Webster, R., Oliver, M.A., 1982. Sample adequately to estimate variograms of soil properties. Journal of Soil Science 43, 177-192.

Weiher, E., Keddy, P.A., 1995. Assembly rules, null models, and trait dispersion: new questions from old patterns. Oikos 74,159-164. 
Whalen, J.K., 2004. Spatial and temporal distribution of earthworm patches in corn field, hayfield and forest systems of southwestern Quebec, Canada. Applied Soil Ecology 27, $143-151$ 


\section{List of tables}

Table 1. Main biometric characteristics and summary statistics of earthworm density in the gallery forest of Carimagua, Colombian "Llanos".

Table 2. Earthworm SADIE aggregation indices and descriptive statistics of spatial clusters' characteristics. Departure from randomness was tested with 5,967 permutations (those permitted by the program). Spatial clustering significance was tested for departure from randomness using 5,967 permutations (those permitted by the program). $\mathrm{NC}=$ number of clusters of each type; PLAND $\%=$ percentage of the sampled area corresponding to a given cluster type, and LCI\% $=$ percentage of the largest cluster of each type, respectively.

Table 3. Summary table of the geostatistical analysis performed on soil variables with the semi-variogram model, and main parameters: the nugget variance $(\mathrm{C} 0)$, the spatial variance $(\mathrm{C})$ and the range (a).

Table 4. Number of pair points and lower and upper limits for each of the 10 distance classes employed in the computation of the correlograms for earthworm species with 9,999 permutations, and significant Bonferroni corrected $\mathrm{P}$ under the $\mathrm{H}_{0}$.

Table 5. Moran's I spatial autocorrelation index obtained for all the soil variables analysed with 9,999 permutations, and significant Bonferroni corrected $\mathrm{P}$ under the null hypothesis $\mathrm{H}_{0}$ (same number of pair points and lower and upper limits for each of the 10 distance classes as in table 4). 
Table 6. Results of the partial Mantel test indicating the correlation coefficients and associated significance within parentheses (10,000 permutations). Probability is corrected after FDR procedure at $0.05 / 3=0.0167$ (one-tailed test). 
Table 1

\begin{tabular}{|c|c|c|c|c|c|c|c|c|c|c|}
\hline \multirow[t]{2}{*}{ Species } & \multirow[t]{2}{*}{ Family } & \multirow[t]{2}{*}{$\begin{array}{l}\text { Ecological } \\
\text { category }\end{array}$} & \multirow[t]{2}{*}{ Pigmentation } & \multicolumn{2}{|l|}{$\begin{array}{l}\text { Size } \\
(\mathrm{mm})\end{array}$} & \multirow[t]{2}{*}{$\begin{array}{l}\text { Weight }^{2} \\
\text { (g.f.w.) }\end{array}$} & \multicolumn{4}{|c|}{ Density } \\
\hline & & & & Length & $\varnothing$ & & Mean & $\mathrm{SE}^{3}$ & Kurt $^{3}$ & Skew $^{3}$ \\
\hline Andiodrilus sp. & Glossoscolecidae & Endogeic & No & 109.0 & 4.4 & $1.38(22)$ & 3.1 & 0.7 & 20.8 & 3.92 \\
\hline Andiorrhinus sp. & Glossoscolecidae & Endo-anecic & $\begin{array}{l}\text { Pink-coloured antero- } \\
\text { dorsal }\end{array}$ & 188.0 & 7.6 & $7.10(10)$ & 0.1 & 0.1 & 100 & 10 \\
\hline Aymara sp. & Glossoscolecidae & Epigeic & Dark-red dorsal & 58.1 & 1.5 & $0.06(15)$ & 6.5 & 1.3 & 15.9 & 3.5 \\
\hline New genus 1 & Octochaetidae & Epigeic & Dark-green dorsal & 117.9 & 3.8 & $0.69(18)$ & 9.5 & 5.1 & 75.6 & 8.4 \\
\hline Glossodrilus sp. & Glossoscolecidae & Endogeic & No & 83.9 & 1.5 & $0.10(13)$ & 8.5 & 1.4 & 4.0 & 2.1 \\
\hline Martiodrilus sp. & Glossoscolecidae & Anecic & Dark-grey antero dorsal & 194.3 & 9.3 & $11.2(29)$ & 10.3 & 1.4 & 2.5 & 1.7 \\
\hline New genus 2 & Ocnerodrilidae & Endogeic & No & 22.8 & 0.7 & $0.006(157)$ & 24.0 & 2.6 & 4.3 & 1.7 \\
\hline
\end{tabular}

${ }^{1}$ After Lavelle, 1981.

${ }^{2}$ Average adult biometric data; g.f.w. $=$ grams fresh weight (unvoided gut). Number of observations within parentheses.

${ }^{3} \mathrm{SE}=$ Standard error; Kurt $=$ Kurtosis; Skew $=$ Skewness. 


\section{Table 2}

\begin{tabular}{|c|c|c|c|c|c|c|c|c|}
\hline \multirow[b]{2}{*}{ Species } & \multirow{2}{*}{$\begin{array}{l}\text { SADIE } \\
I_{a}\end{array}$} & \multicolumn{2}{|c|}{ Local clusters } & \multicolumn{5}{|c|}{ Spatial clustering characteristics } \\
\hline & & $\mathrm{v}_{\mathrm{j}}$ & $\mathrm{v}_{\mathrm{i}}$ & Type & Significance & $\mathrm{NC}$ & PLAND(\%) & $\mathrm{LCI}(\%)$ \\
\hline \multirow[t]{3}{*}{ Andiodrilus sp. } & 1.097 & -1.097 & 1.111 & Gap & NS & 6 & 21 & 10 \\
\hline & & & & Random & & 1 & 77 & 77 \\
\hline & & & & Patch & NS & 2 & 2 & 1 \\
\hline \multirow[t]{3}{*}{$\underline{\text { Andiorrhinus sp. }}$} & 0.974 & -0.973 & 1.009 & Gap & NS & 0 & - & - \\
\hline & & & & Random & & & - & - \\
\hline & & & & Patch & NS & 0 & - & - \\
\hline \multirow[t]{3}{*}{ Aymara sp. } & $1.408 *$ & $-1.404 *$ & $1.292 *$ & Gap & $*$ & 2 & 24 & 22 \\
\hline & & & & Random & & 1 & 67 & 67 \\
\hline & & & & Patch & $*$ & 5 & 9 & 4 \\
\hline \multirow[t]{3}{*}{ New genus 1} & 1.054 & -1.050 & 1.077 & Gap & NS & 5 & 19 & 8 \\
\hline & & & & Random & & 1 & 79 & 79 \\
\hline & & & & Patch & NS & 2 & 2 & 1 \\
\hline \multirow[t]{3}{*}{ Glossodrilus sp. } & 1.172 & -1.167 & 1.161 & Gap & NS & 7 & 15 & 4 \\
\hline & & & & Random & & 1 & 76 & 76 \\
\hline & & & & Patch & NS & 6 & 9 & 3 \\
\hline \multirow[t]{3}{*}{ Martiodrilus sp. } & 1.110 & -1.094 & 1.178 & Gap & NS & 6 & 15 & 6 \\
\hline & & & & Random & & 1 & 79 & 79 \\
\hline & & & & Patch & NS & 4 & 6 & 2 \\
\hline \multirow[t]{3}{*}{ New genus 2} & 1.154 & -1.140 & 1.061 & Gap & NS & 3 & 16 & 9 \\
\hline & & & & Random & & 1 & 77 & 77 \\
\hline & & & & Patch & NS & 4 & 7 & 4 \\
\hline
\end{tabular}

$\mathrm{I}_{\mathrm{a}}=$ global index of aggregation; $\mathrm{v}_{\mathrm{i}}=$ mean positive index (patch); $\mathrm{v}_{\mathrm{j}}=$ mean negative index (gap) (see Perry 1998 for details). $*_{\mathrm{p}}<0.05$; NS, not significant. 
Table 3

\begin{tabular}{|c|c|c|c|c|}
\hline Soil variable $^{1}$ & Model & $\mathrm{CO}$ & $\mathrm{C}$ & $\mathrm{a}$ \\
\hline $\operatorname{Litter}\left(\mathrm{g} \mathrm{m}^{-2}\right)$ & Spherical & 0.240 & 0.191 & 14.1 \\
\hline Moisture (w/w \%) & Flat & 0.007 & - & - \\
\hline $\mathrm{P}_{0-5}(\mathrm{ppm})$ & Spherical & 0.005 & 0.0045 & 17.1 \\
\hline $\mathrm{P}_{5-10}(\mathrm{ppm})$ & Linear & 0.020 & - & - \\
\hline $\mathrm{SOC}_{0-5}\left(\mathrm{~g} \mathrm{~kg}^{-1}\right)$ & Spherical & 0.011 & 0.022 & 8.1 \\
\hline $\mathrm{SOC}_{5-10}\left(\mathrm{~g} \mathrm{~kg}^{-1}\right)$ & Spherical & 0.010 & 0.014 & 4.0 \\
\hline $\mathrm{N}_{0-5}\left(\mathrm{~g} \mathrm{~kg}^{-1}\right)$ & Spherical & 0.005 & 0.032 & 9.3 \\
\hline $\mathrm{N}_{5-10}\left(\mathrm{~g} \mathrm{~kg}^{-1}\right)$ & Spherical & 0.019 & 0.007 & 6.2 \\
\hline$C: \mathrm{N}_{0-5}$ & Spherical & 0.002 & 0.005 & 9.1 \\
\hline $\mathrm{C}: \mathrm{N}_{5-10}$ & Spherical & 0.019 & 0.018 & 6.3 \\
\hline FiRL $\left(m \text { sample }^{-1}\right)^{\dagger}$ & Spherical & 0.151 & 0.230 & 346.5 \\
\hline CoRL $\left(\mathrm{m} \mathrm{sample}{ }^{-1}\right)^{\dagger}$ & Spherical & 0.265 & 0.387 & 398.4 \\
\hline FiRW $\left(\text { g sample }^{-1}\right)^{\dagger}$ & Spherical & 0.130 & 0.052 & 17.3 \\
\hline CoRW $\left(\text { g sample }^{-1}\right)^{\dagger}$ & Flat & 1.380 & - & - \\
\hline PR2 (MPa) & Linear & 0.364 & - & - \\
\hline PR5 (MPa) & Linear & 0.439 & - & - \\
\hline PR10 (MPa) & Linear & 0.651 & - & - \\
\hline$<0.250 \mathrm{Agg}(\%)$ & Linear & 0.519 & - & - \\
\hline $\operatorname{Agg} 0.250-1(\%)$ & Spherical & 0.041 & 0.033 & 25.4 \\
\hline $\operatorname{Agg} 1-5(\%)$ & Spherical & 0.029 & 0.020 & 19.8 \\
\hline $\mathrm{Agg}>5(\%)$ & Spherical & 0.014 & 0.019 & 19.7 \\
\hline$\rho_{\mathrm{d}}\left(\mathrm{g} \mathrm{cm}^{-3}\right)$ & Spherical & 0.015 & 0.028 & 32.7 \\
\hline Comp. (\%) & Flat & 0.007 & - & - \\
\hline Cond. $\left(\mathrm{cm} \mathrm{h}^{-1}\right)$ & Flat & 0.006 & - & - \\
\hline $\operatorname{Litter}\left(\mathrm{g} \mathrm{m}^{-2}\right)$ & Linear & 1.461 & - & - \\
\hline
\end{tabular}

\footnotetext{
${ }^{I}$ P, Phosphorous; SOC, Soil organic carbon; N, Nitrogen; FiRL, Fine root length; CoRL, Coarse root length; FiRW, Fine root weight; CoRW, Coarse root weight; PR, Penetration resistance; $<0.250$ $\operatorname{Agg}(\%)$, percentage of aggregates $<0.250 \mathrm{~mm} ; \rho_{\mathrm{d}}$, Bulk density; Comp, Compaction (Susceptibility to); Cond, Hydraulic conductivity. 0-5: soil depth 0- $5 \mathrm{~cm}$; 5-10: soil depth 5-10 cm; MPa: MegaPascals.

${ }^{\dagger}$ Sample refers to a soil core of $10 \mathrm{~cm}$ dia. and $15 \mathrm{~cm}$ long $\left(1,178.1 \mathrm{~cm}^{3}\right)$.
} 


\section{Table 4}

\begin{tabular}{|c|c|c|c|c|c|c|c|c|c|}
\hline \multirow{2}{*}{$\begin{array}{l}\text { Distance } \\
\text { class }\end{array}$} & \multirow{2}{*}{$\begin{array}{l}\text { Number of } \\
\text { pair points }\end{array}$} & \multirow{2}{*}{$\begin{array}{l}\text { Lower } \\
\text { limit }(\mathrm{m})\end{array}$} & \multirow{2}{*}{$\begin{array}{l}\text { Upper } \\
\text { limit (m) }\end{array}$} & \multicolumn{6}{|l|}{ Species } \\
\hline & & & & And $^{1}$ & Aym & $\mathrm{Ng} 1$ & Glo & Mrt & $\mathrm{Ng} 2$ \\
\hline 1 & 180 & 0 & 5.8 & 0.0130 & $0.2206 * * *$ & $0.1627 * * *$ & -0.0841 & 0.0334 & -0.1011 \\
\hline 2 & 610 & 5.8 & 11.6 & 0.0047 & 0.0244 & -0.0355 & 0.0069 & 0.0158 & $0.0740 *$ \\
\hline 3 & 520 & 11.6 & 17.4 & -0.0619 & -0.0519 & -0.0283 & 0.0470 & 0.0178 & -0.0226 \\
\hline 4 & 850 & 17.4 & 23.1 & -0.0256 & -0.0009 & -0.0251 & 0.0178 & -0.0151 & -0.0158 \\
\hline 5 & 680 & 23.1 & 28.9 & 0.0368 & -0.0099 & -0.0087 & 0.0275 & $-0.0946 *$ & 0.0276 \\
\hline 6 & 724 & 28.9 & 34.7 & 0.0156 & -0.0414 & -0.0062 & -0.0701 & -0.0376 & $-0.1045 * *$ \\
\hline 7 & 758 & 34.7 & 40.5 & -0.0027 & -0.0034 & -0.0119 & -0.0427 & 0.0279 & 0.0033 \\
\hline 8 & 396 & 40.5 & 46.3 & -0.0413 & -0.0818 & -0.0120 & -0.0150 & -0.0425 & 0.0519 \\
\hline 9 & 162 & 46.3 & 52.1 & -0.0699 & 0.0513 & 0.0034 & -0.0202 & $0.1596 *$ & -0.1055 \\
\hline 10 & 60 & 52.1 & 57.9 & -0.1264 & -0.1402 & 0.0290 & -0.0389 & -0.0612 & 0.0379 \\
\hline
\end{tabular}

\footnotetext{
${ }^{1}$ And $=$ Andiodrilus $;$ Aym $=$ Aymara $; \mathrm{Ng}=$ New genus $;$ Glo $=$ Glossodrilus $;$ Mrt $=$ Martiodrilus

$* \mathrm{P}<0.05 ; * * \mathrm{P}<0.01 ; * * * \mathrm{P}<0.001 ; \mathrm{NS}$, Not significant.
} 
Table 5

\begin{tabular}{|c|c|c|c|c|c|c|c|c|c|c|c|}
\hline \multirow{2}{*}{$\begin{array}{l}\text { Soil } \\
\text { variable }^{1}\end{array}$} & \multicolumn{10}{|c|}{ Distance class } & \multirow{2}{*}{$\begin{array}{l}\text { Overall } \\
\text { corrected P }\end{array}$} \\
\hline & 1 & 2 & 3 & 4 & 5 & 6 & 7 & 8 & 9 & 10 & \\
\hline Litter & $0.207 * *$ & -0.025 & -0.065 & $-0.083 *$ & 0.044 & $0.096 * *$ & -0.016 & $-0.131 *$ & -0.040 & 0.063 & 0.018 \\
\hline Moisture & $0.189 * *$ & $0.201 * * *$ & $0.082 *$ & 0.013 & -0.069 & $-0.080 *$ & $-0.131 * * *$ & $-0.106 *$ & -0.015 & -0.206 & $<0.001$ \\
\hline$P_{0-5}$ & $0.353 * * *$ & $0.206 * * *$ & $0.123 * *$ & $0.106 * * *$ & -0.017 & $-0.106 * *$ & $-0.172 * * *$ & $-0.209 * * *$ & $-0.398 * * *$ & $-0.417 * *$ & $<0.001$ \\
\hline$P_{5-10}$ & $0.479 * * *$ & $0.355 * * *$ & $0.251 * * *$ & $0.125 * * *$ & -0.008 & $-0.169 * * *$ & $-0.265 * * *$ & $-0.354 * * *$ & $-0.464 * * *$ & $-0.637 * * *$ & $<0.001$ \\
\hline $\mathrm{SOC}_{0-5}$ & $0.142 *$ & -0.024 & -0.072 & 0.029 & -0.015 & -0.012 & -0.036 & 0.017 & 0.092 & $-0.322 * *$ & NS \\
\hline $\mathrm{SOC}_{5-10}$ & $0.250 * * *$ & $0.141 * * *$ & $0.096 * *$ & $0.052 *$ & -0.031 & $-0.078 *$ & -0.043 & $-0.223 * * *$ & $-0.297 * * *$ & $-0.342 * *$ & $<0.001$ \\
\hline $\mathrm{N}_{0-5}$ & $0.207 * *$ & -0.050 & $-0.095 *$ & 0.000 & -0.008 & 0.010 & -0.004 & 0.026 & 0.068 & $-0.385 * *$ & 0.026 \\
\hline $\mathrm{N}_{5-10}$ & 0.011 & 0.006 & -0.025 & 0.005 & -0.009 & -0.073 & 0.007 & 0.033 & 0.011 & -0.099 & NS \\
\hline $\mathrm{C}: \mathrm{N}_{0-5}$ & $0.172 *$ & -0.031 & -0.060 & 0.018 & 0.057 & -0.022 & -0.073 & -0.048 & 0.023 & 0.020 & NS \\
\hline$C: \mathrm{N}_{5-10}$ & $0.124 *$ & $0.096 * * *$ & $0.092 * *$ & $0.057 * *$ & 0.029 & -0.022 & $-0.122 * * *$ & $-0.173 * * *$ & $-0.302 * * *$ & $-0.265 *$ & $<0.001$ \\
\hline FiRL & $0.195 * *$ & $0.070 *$ & 0.048 & $-0.074 *$ & -0.053 & -0.043 & -0.006 & -0.026 & -0.023 & -0.036 & NS \\
\hline CoRL & 0.041 & 0.061 & 0.012 & -0.009 & 0.013 & $-0.102 * *$ & -0.014 & -0.022 & -0.043 & -0.023 & NS \\
\hline FiRW & $0.141 *$ & $0.079 *$ & -0.030 & -0.030 & $0.085 * *$ & 0.008 & $-0.099 * *$ & $-0.170 * * *$ & -0.106 & 0.196 & 0.005 \\
\hline CoRW & 0.040 & 0.020 & 0.022 & -0.035 & $-0.077 *$ & -0.040 & -0.006 & $0.087 *$ & 0.008 & -0.047 & NS \\
\hline $\mathrm{PR} 2.5^{2}$ & $0.827 * * *$ & $0.652 * * *$ & $0.452 * * *$ & $0.163 * * *$ & $-0.09 *$ & $-0.284 * * *$ & $-0.392 * * *$ & $-0.532 * * *$ & $-0.773 * * *$ & $-1.008 * * *$ & $<0.001$ \\
\hline Agg0.053-0.125 & $0.142 *$ & 0.055 & 0.001 & $-0.100 * *$ & -0.067 & 0.019 & -0.019 & 0.000 & -0.001 & $0.315 * *$ & 0.037 \\
\hline Agg0.125-0.25 & $0.277 * * *$ & $0.219 * * *$ & $0.092 *$ & -0.025 & -0.035 & -0.074 & $-0.104 * *$ & $-0.120 *$ & $-0.302 * * *$ & -0.077 & $<0.001$ \\
\hline Agg0.25-0.5 & $0.239 * * *$ & $0.125 * * *$ & $0.102 * *$ & -0.006 & -0.045 & -0.026 & $-0.115 * *$ & -0.027 & $-0.342 * * *$ & -0.099 & $<0.001$ \\
\hline Agg0.5-1 & $0.250 * * *$ & $0.188 * * *$ & $0.071 *$ & 0.013 & -0.026 & -0.040 & $-0.122 * * *$ & $-0.133 * *$ & $-0.294 * * *$ & -0.228 & $<0.001$ \\
\hline Agg1-2 & $0.260 * * *$ & $0.137 * * *$ & -0.041 & 0.009 & -0.010 & 0.004 & $-0.081 *$ & $-0.129 * *$ & $-0.218 * *$ & -0.228 & $<0.001$ \\
\hline Agg2-5 & $0.437 * * *$ & $0.330 * * *$ & $0.174 * * *$ & $0.072 * *$ & -0.045 & $-0.111 * *$ & $-0.187 * * *$ & $-0.228 * * *$ & $-0.510 * * *$ & $-0.767 * * *$ & $<0.001$ \\
\hline Agg5-10 & -0.029 & 0.020 & 0.009 & -0.005 & -0.002 & 0.011 & -0.025 & -0.073 & -0.058 & -0.107 & NS \\
\hline Agg $>10$ & $0.291 * * *$ & $0.212 * * *$ & $0.100 * *$ & 0.011 & -0.041 & $-0.083 *$ & $-0.116 * *$ & $-0.117 *$ & $-0.321 * * *$ & $-0.313 *$ & $<0.001$ \\
\hline BD & $0.230 * * *$ & $0.095 * *$ & 0.037 & -0.013 & -0.045 & $-0.081 *$ & -0.022 & -0.040 & -0.103 & -0.283 & 0.008 \\
\hline
\end{tabular}




\begin{tabular}{|c|c|c|c|c|c|c|c|c|c|c|c|}
\hline Comp & 0.094 & $0.072 *$ & -0.081 & 0.000 & 0.004 & -0.030 & -0.020 & -0.028 & -0.048 & -0.251 & NS \\
\hline Conduc & $0.144 *$ & 0.053 & 0.018 & -0.001 & -0.049 & -0.021 & -0.071 & 0.003 & -0.023 & -0.177 & NS \\
\hline
\end{tabular}

${ }^{1}$ Same legend as in Table 3.

${ }^{2}$ Correlograms for the variable resistance to penetration at $5,10,15$ and $20 \mathrm{~cm}$ were identical to that obtained for $2.5 \mathrm{~cm}$ depth.

$* \mathrm{P}<0.05 ; * * \mathrm{P}<0.01 ; * * * \mathrm{P}<0.001 ; \mathrm{NS}$, Not significant. 


\section{Table 6}

\begin{tabular}{|c|c|c|c|c|c|c|}
\hline Soil variable $^{1}$ & $\underline{\text { Andiodrilus }}$ & Aymara & New genus 1 & $\underline{\text { Glossodrilus }}$ & $\underline{\text { Martiodrilus }}$ & New genus 2 \\
\hline Litter & -0.270 & 0.343 & 0.176 & -0.149 & 0.088 & -0.206 \\
\hline Moisture & 0.031 & -0.312 & 0.068 & 0.208 & -0.085 & 0.147 \\
\hline$P_{0-5}$ & -0.034 & 0.045 & 0.086 & -0.084 & 0.230 & 0.222 \\
\hline$P_{5-10}$ & -0.116 & 0.109 & -0.181 & -0.043 & 0.301 & 0.085 \\
\hline $\mathrm{SOC}_{0-5}$ & -0.203 & 0.161 & $0.662 * *$ & -0.139 & -0.045 & -0.160 \\
\hline $\mathrm{SOC}_{5-10}$ & 0.012 & -0.221 & $-0.420 *$ & -0.012 & 0.153 & 0.157 \\
\hline $\mathrm{N}_{0-5}$ & -0.244 & 0.325 & $0.546 * *$ & -0.179 & 0.025 & -0.199 \\
\hline $\mathrm{N}_{5-10}$ & -0.166 & -0.037 & $0.462 * *$ & -0.057 & -0.048 & -0.265 \\
\hline $\mathrm{C}: \mathrm{N}_{0-5}$ & 0.059 & -0.235 & 0.189 & 0.099 & -0.119 & 0.133 \\
\hline $\mathrm{C}: \mathrm{N}_{5-10}$ & 0.122 & -0.180 & $-0.538 * *$ & -0.004 & 0.172 & $0.341 * *$ \\
\hline FiRL & -0.090 & $0.442 * *$ & -0.011 & -0.122 & -0.016 & -0.031 \\
\hline CoRL & -0.216 & 0.140 & -0.121 & -0.148 & -0.042 & -0.148 \\
\hline FiRW & -0.006 & 0.349 & 0.015 & -0.121 & -0.028 & -0.080 \\
\hline CoRW & -0.016 & 0.432 & -0.113 & -0.083 & -0.162 & 0.014 \\
\hline PR2 & $-0.407 *$ & -0.030 & -0.145 & 0.253 & 0.131 & 0.050 \\
\hline PR5 & $-0.472 * *$ & 0.021 & -0.141 & 0.164 & 0.100 & 0.058 \\
\hline PR10 & $-0.450 * *$ & 0.033 & -0.111 & 0.157 & 0.044 & 0.017 \\
\hline$<0.250 \mathrm{Agg}$ & -0.102 & $-0.345 * *$ & -0.204 & 0.013 & -0.287 & -0.001 \\
\hline Ag1 & -0.229 & -0.186 & 0.032 & -0.141 & -0.213 & -0.107 \\
\hline Ag2 & $-0.383 * *$ & 0.1034 & 0.272 & $-0.373 * *$ & 0.094 & -0.191 \\
\hline Ag10 & 0.358 & 0.020 & -0.182 & 0.311 & 0.027 & 0.169 \\
\hline Bulk & 0.271 & -0.061 & $-0.746 * *$ & 0.235 & 0.068 & 0.199 \\
\hline Comp & 0.106 & -0.317 & $-0.526 * *$ & 0.189 & -0.067 & 0.284 \\
\hline Conduc & -0.098 & 0.178 & $0.503 * *$ & -0.242 & -0.030 & -0.185 \\
\hline
\end{tabular}

${ }^{1}$ Same legend as in Table 4.

$* \mathrm{p}<0.05, * * \mathrm{p}<0.01, * * * \mathrm{p}<0.001$ 


\section{$1 \quad$ Figure captions}

2 Figure 1. Overlaid contour and classed red-blue post maps (surfer) of SADIE clustering

3 indices for counts of all species (except Andiorrhinus sp.) Blue shading and darker blue

4 dots indicate significant gaps (index values $>-1.5$ ); and red shading and darker red dots

5 indicate significant patches (index values > 1.5). Black dots indicate units with

6 clustering that exceeds expectation although not significantly $(>2$ or $<-1)$. Open dots

7 indicate clustering below expectation $(<1$ or $>-1)$.

8 Figure 2. Estimated semi-variograms and contour plot of a) SOC concentration ( $\mathrm{g} \mathrm{kg}$

9 soil $\left.\left.^{-1}\right), \mathrm{b}\right) \mathrm{P}$ concentration ( $\left.\left.\mathrm{ppm}\right), \mathrm{c}\right)$ hydraulic conductivity $\left(\mathrm{cm} \mathrm{h}^{-1}\right)$, and d) proneness to 10 compaction $(\%)$ 

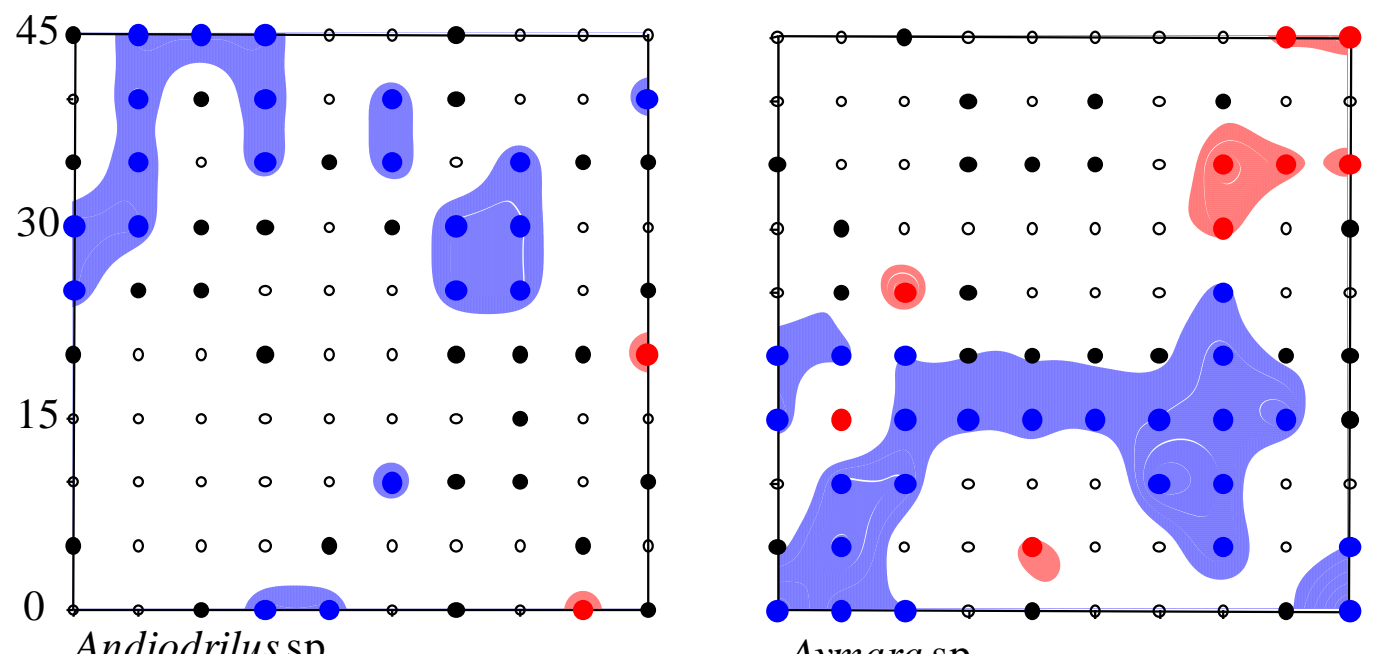

Andiodrilus sp.

Aymara sp.
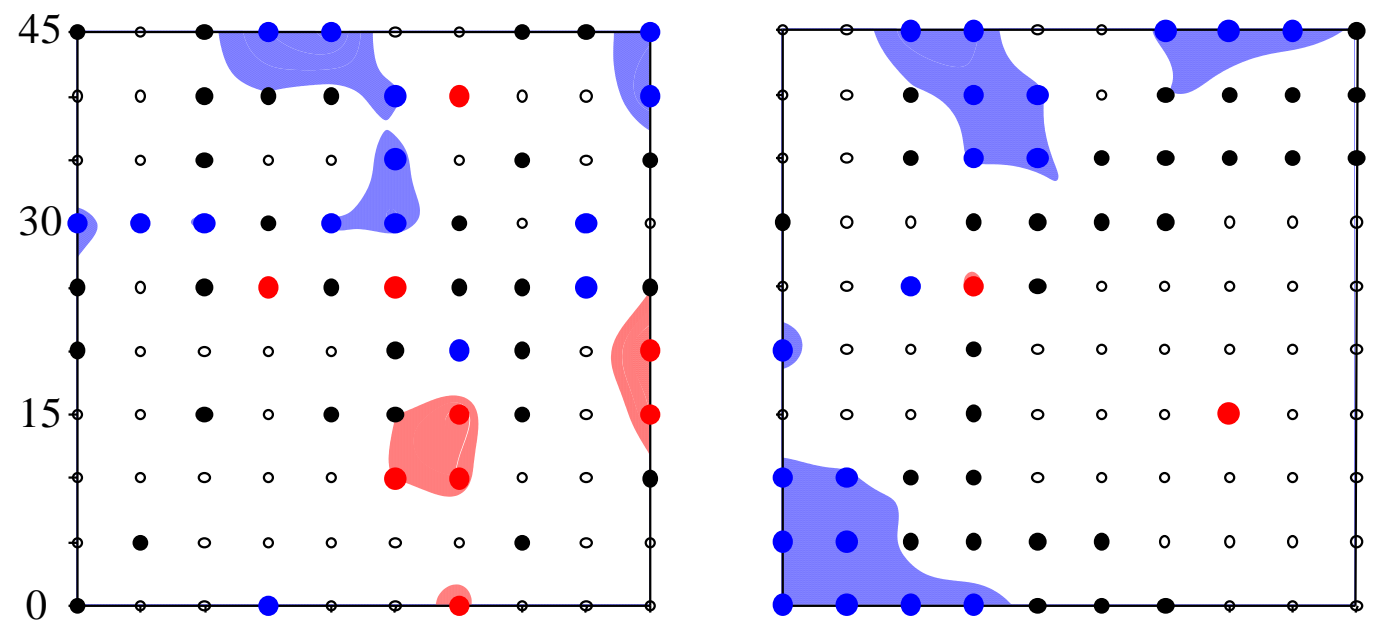

Glossodrilus sp.

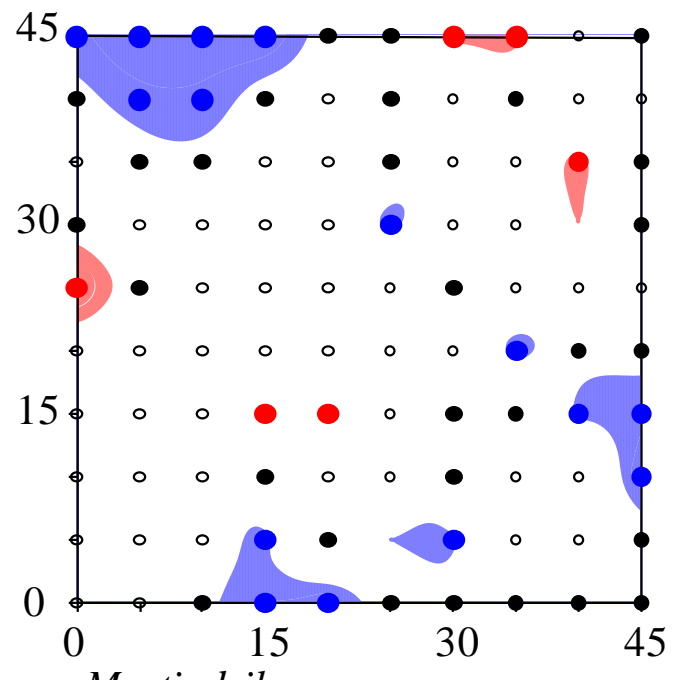

Martiodrilus sp.

Figure 1 - Jiménez, Decaëns, Amézquita, Rao, Thomas, Lavelle

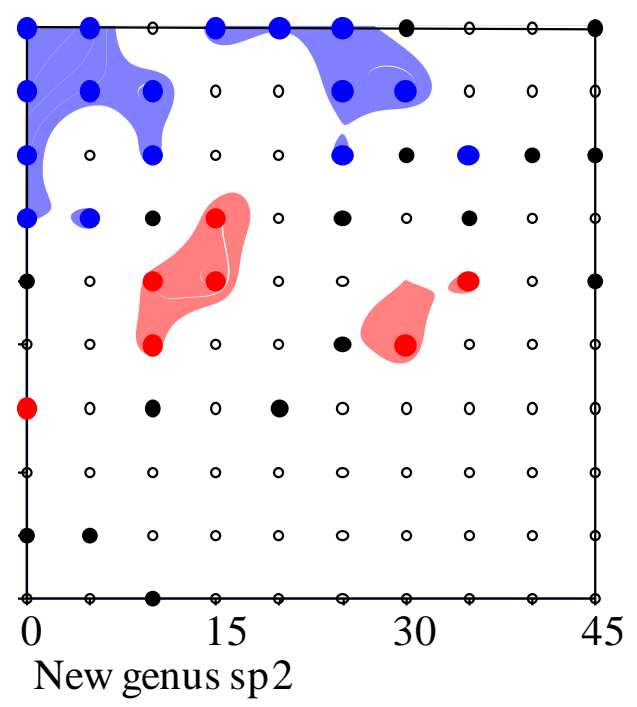



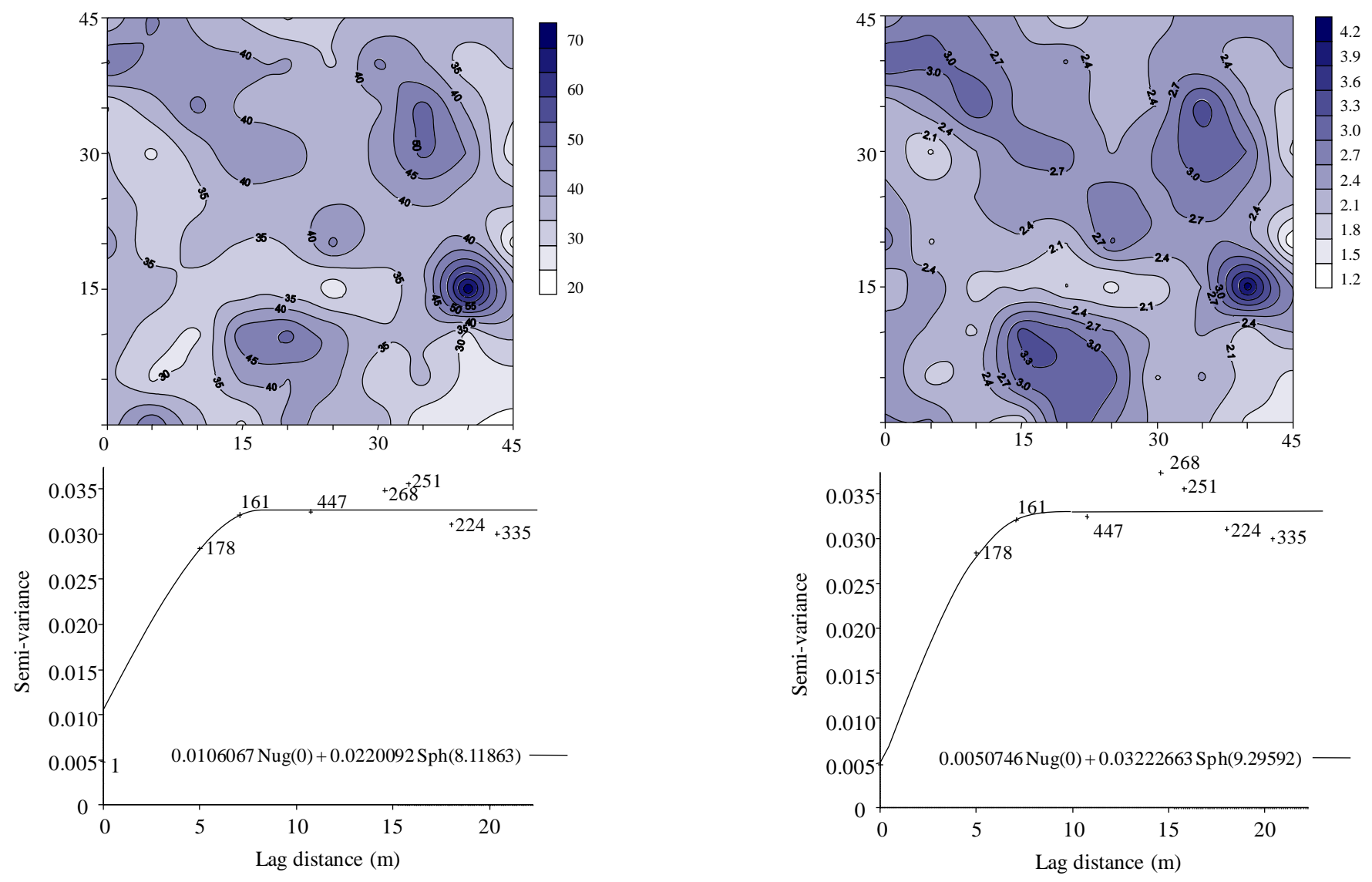

2a)

2b) 

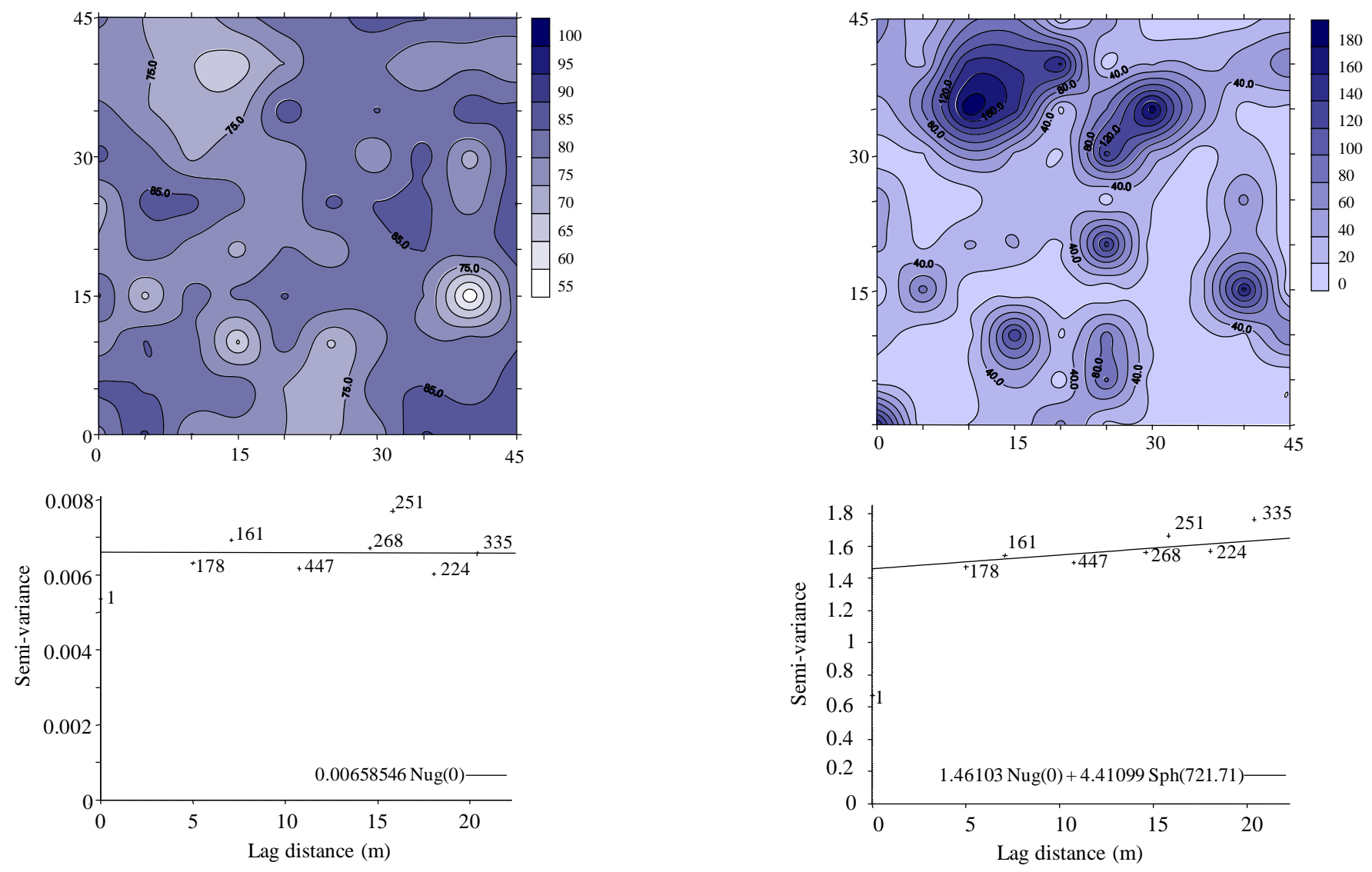

2c)

2d)

Figure 2 - Jiménez, Decaëns, Amézquita, Rao, Thomas, Lavelle 